\title{
Energy Consumption, Thermal Performance and Thermal Comfort in Public School Buildings in Jordan
}

\author{
Abdulsalam A. Alshboul \\ Department of Architecture, Faculty of Engineering and Technology, University of Jordan, Amman 11942, Jordan
}

\begin{abstract}
Good learning outputs in schools require an acceptable physical environment inside schools. Whatever the climatic context that surrounds any school buildings, energy flows of different types should be provided. Concerns may include thermal environment, luminous environment and acoustics environment. Types of energy used are an important variable that contributes to thermal comfort. Physical structure of the school building is another factor to be taken into consideration. This article established a relationship between thermal comfort inside schools and types of energy flows which have been consumed to maintain the level of comfort required, controlled by the building fabric and consequent economic factors that affect energy consumption of school buildings. Different approaches were applied in order to achieve the research objectives. Field surveys, field measurements and analyzing historical data were the most approaches followed to implement this study. The final outputs of this work have a national value nationwide: establishing a relationship among thermal comfort, energy flows and building fabric is of importance. Furthermore, it is of great importance to the decision maker for educational facilities. Research will also establish a wide platform based on scientific investigations for developing climate responsive school architecture in Jordan.
\end{abstract}

Key words: School buildings, energy, thermal comfort, educational environments, thermal performance, Jordan.

\section{Introduction}

One of the major pillars of the educational process is the building itself or the physical environment of the educational buildings. This is considered as the container of the whole educational process. Such environments have to be well designed functionally and physically to be able to achieve the targeted educational outputs. The functional aspect of school design is of major importance and this includes circulation patterns, sequence of space ordering to fit with functional activities, spatial structure, colors and sufficiency of functional areas to fit with the assigned functions for different activities in the school buildings. Many other factors which the designer should consider while making his design decisions like the external appearance, texture, and massing and many other variables are of great importance.

Corresponding author: Abdulsalam A. Alshboul, Ph.D., associate professor, research fields: environmental design, energy and buildings, and building physics. E-mail: alshboul@ju.edu.jo.
Public educational sector in Jordan houses around 900,000 students in around 6,008 school buildings distributed throughout the Jordanian territories. School buildings stand on a total site area of about $35,852,711$ donums and total number of classrooms in Jordan counts for 64,679 classrooms occupying around $170,784 \mathrm{~m}^{2}[1]$.

The academic year starts from August each year and ends on June which is divided into two semesters each year: the total number of teaching days is 195 days approximately, the teaching day starts from 8:00 am and ends around 14:00 pm. Students stay in the classroom environment 6 hours daily and almost 1,170 hours yearly, and this long time duration implies how important it is to create a suitable environment inside the classroom, taking into consideration that the total number the students stay in the classroom in their whole learning life in the classroom is almost $14,040 \mathrm{~h}$.

\subsection{Design Guidelines for School Buildings in Jordan}

An architectural design guideline for government 
schools is a publication issued by the ministry of education in the year 2003 as a base for the architects who design school buildings [2].

The design guidelines start by explaining the main objectives of the guidelines, definition of users, description of the physical environment, types and spatial requirements of schools, and finally end with special requirements for building accessibility. The guide covers almost the most important arguments related to school design, leaving a large margin for the architect to formulate any design concept by his own creative way.

Regarding thermal design and comfort mentioned in the design guidelines, which are directly related to research problem, this was mentioned under article No. 6 page 11 [1], which could be summarized as follows:

(1) A description of how the architect must consider climatic aspects differentiation between different climatic regions. Article 6.1 states: "the wide variety of topographical areas in Jordan produces a wide range of climate which, in turn, requires a wide range of building design solutions to provide a thermally comfortable environment for teaching and learning activities" [1]. This measure is followed by guiding the architect about how to apply natural measures to make use of sun, wind and vegetation and then how to tackle the issue of direct sunlight and its relationship with classroom environment. Natural ventilation is ensured by guiding the architect to design opposite openings in the classroom;

(2) Visual balance, where a uniform luminance distribution in the classroom is required, avoiding excessive glare and poor lighting quality at the same time;

(3) Acoustical quality, which includes guidelines about avoiding noise and background noise, which, in turn, ensures the importance of the physical environment of the classroom in the learning process;

(4) Safety in schools and, finally, furniture and equipment [1].

\subsection{School Layout Typologies}

School plan layout and design developed through time, passing through multiple developments and improvements. Many factors affected such improvements and developments like concerns about pupils' safety, indoor air quality, thermal comfort and energy consumption. Fig. 1 shows some examples of school plan layouts in Jordan. The linear layout was the dominant aspect in the majority of classroom wings and then it developed to different layout variations.

The U-shape school, where the courtyard is used for external activities, constructed in the 1960s and 1970s, was the first plan layout to be used in Jordan and then, a set of more developed plan layouts were adopted to create more comfortable educational environments.

Recently, thermal insulation and climate responsive design aspects were included in school design practice, due to the national energy policies.

\section{Quantification of Energy Flows}

\subsection{Energy Consumption in Schools}

School buildings need a certain quantity of energy flows in order to be well operated. Type and quantity of fuel depend upon what aspects of school building should be operated. According to frequency of occupation, function, type of space activity and other aspects, ministry of education decides type of fuel to be used for heating in cold season, and fuel types are mainly LPG (liquefied petroleum gas), kerosene and diesel.

Since long time ago, climatic aspects, energy and natural resources requirements were of major importance to building design. As well, minimizing energy consumption is an economic and environmental target and this important element "energy" contributes to supporting the fundamental goal of design which is improving the quality of environments we live [3].

It is very important to consider the environmental effects due to energy consumption, like those of $\mathrm{CO}_{2}$ emissions: the major concern on the international level 

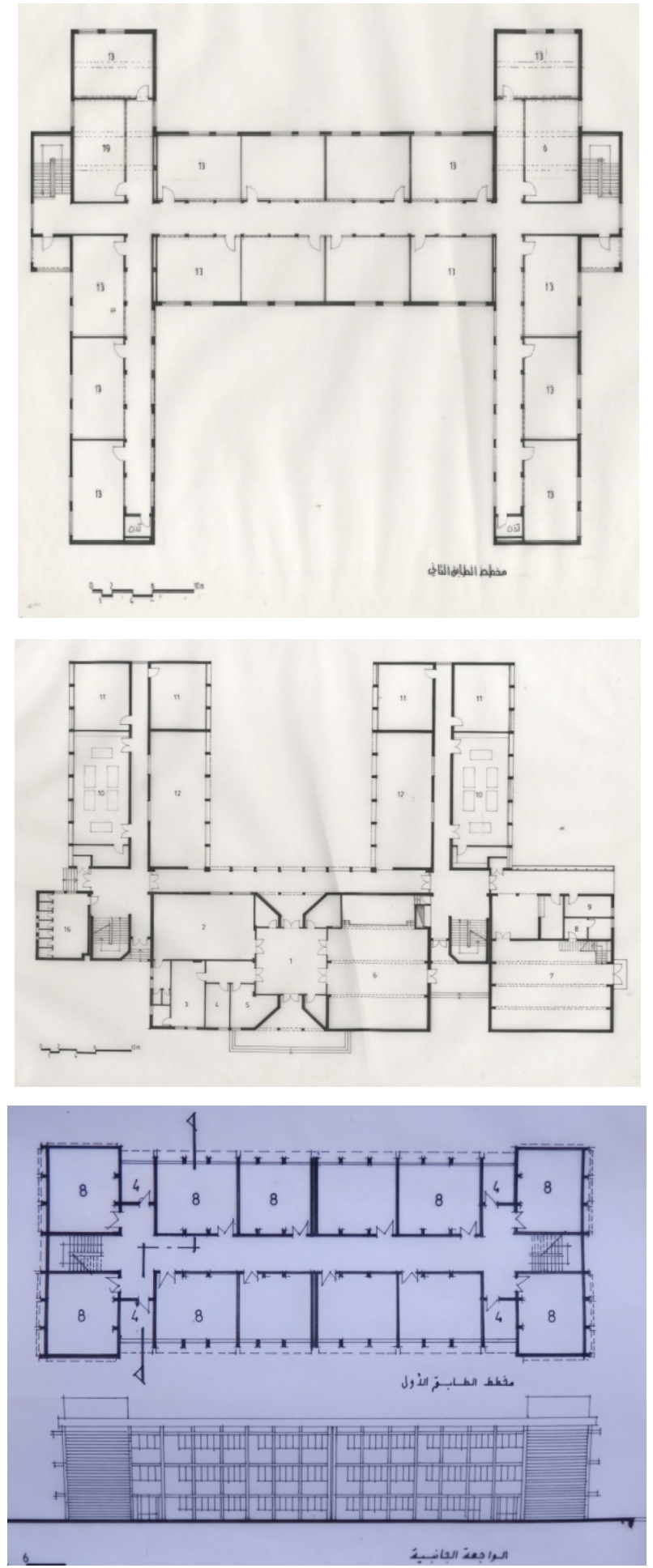

Fig. 1 The most common school plan layouts in public educational sector, displayed in different orientations on sites.

is reducing $\mathrm{CO}_{2}$ emissions and other carbon gases. Trend in different countries of the world is to include this issue in their building regulations and building codes, an impinging factor to consider in reducing the risk of ozone depletion layer.

\subsection{Thermal Comfort}

ASHRAE (American Society for Heating, Refrigerating and Air Conditioning Engineers) defines thermal comfort as "that condition of mind which expresses satisfaction with the thermal environment" [4].

The level of comfort is often expressed using the thermal sensation scale. The average thermal sensation response for a large group of people is called the PMV (predicted mean vote). Table 1 shows the standard ASHRAE thermal sensation scale and corresponding Bedford thermal scale $[1,5]$ in which large group of people vote accordingly [4].

\subsection{Schools Energy Consumption by Type}

The operation of schools in Jordan requires necessarily a certain flow of energy, and in order to operate different activities or to maintain a certain level of thermal comfort, illumination and many other electrical equipment, different fuel types are used. The first and most important energy type is electricity, which is considered as the finest form of energy and the most important energy type to be saved, as the production of electricity reduces $70 \%$ of the original energy [6].

The second type of fuel used in schools is fossil fuels, mainly diesel and kerosene, which are used for heating in two ways to operate heaters: in schools without central heating plants and in schools with central heating plants.

Table 1 ASHRAE and Bedford thermal sensation scales.

\begin{tabular}{lll}
\hline Value & ASHRAE scale & Bedford scale \\
\hline+3 & Hot & Much too warm \\
+2 & Warm & Too warm \\
+1 & Slightly warm & Comfortably warm \\
0 & Neutral & Comfortable \\
-1 & Slightly cool & Comfortably cool \\
-2 & Cool & Too cool \\
-3 & Cold & Much too cool \\
\hline
\end{tabular}


The third type of fuel is LPG which is used mainly for cooking. No figures have been recorded in the ministry of education for this type of fuel [1]. Consumption rates of different fuel types have been obtained from different educational directorates, and some missing figures from different directorates are observed.

\section{Literature and Previous Studies}

Work on energy conservation by design and its relationship with thermal comfort are vast and much scientific work has been recorded. In our literature review here, we will divide it into two major parts: international research work and national research work.

School building design generally and energy consumption in schools specifically gained a lot of interest many years ago, and this happened in many different countries worldwide. Wiles [6] paid attention to the issue of energy consumption in school buildings through a detailed study of two large schools in the USA about how they responded to the energy crisis in the year 1977 by describing the factors underlined different responses of the studies schools to the energy crisis [7].

Two large schools in Birmingham were studied by Hildon and Howrie [7], through a national project of "Energy Conservation Demonstration Project", and the main objective of the study was to study and analyze different energy conservation measures of two major school buildings by observing different aspects of the design, construction and operation of the schools, while concentrating on most important issues of energy related parameters like form, fabric, insulation, reduced air infiltration, low areas of glazing, zoning of services and heat recovery [8].

A later study [9], in Britain, discussed specification regarding educational buildings the British Government issued in the year 1979 entitled "Guidelines for environmental design and fuel conservation in educational buildings" [10] which included energy conservation measures as a response to the energy crisis during the 70 s of the last century. The guidelines set new indoor temperatures for different spaces of educational buildings to maintain comfort levels in British school buildings [11]. The author tried to explain reasons of absenteeism in British schools by establishing a correlation between discomfort in classrooms and absenteeism, as it was observed that the less temperature in the classroom, the more absenteeism percent was recorded [9].

Santamouris et al. [8] documented the actual energy consumption of school buildings in Greece as an introduction to the study of different scenarios for energy saving during schools operation. They found that among different building types: hospitals, hotels, offices, commercial buildings, schools consume the least energy and they indicated $93 \mathrm{kWh} / \mathrm{m}^{2}$ for school buildings. They tried to define energy saving strategies for each of energy consumption aspects related to school buildings, energy saving from heating, artificial lighting and cooling [12].

In a later study, school buildings in Slovenia were surveyed for energy quantification and indoor air quality, where it has been found that schools are high energy consumers and, at the same time, provide poor indoor air quality. This was due to many defects related to thermal performance of the studied school buildings, apart from the fact that those schools have central heating plants, which led to a final recommendation of replacing such heating systems with energy efficient blown air systems for double functioning of both heating in winter and air conditioning in summer [13].

Electrical and thermal energy consumption indexes have been calculated for high schools in central Italy in order to find convenient strategies for energy savings in those schools. It shows that a potential of $38 \%$ thermal energy savings could be achieved and a reduction of electricity consumption of about $46 \%$ is possible if certain strategies are applied to school sector in the area of study in Italy [14].

A study of developing energy performance 
benchmarks and energy ratings has been established for Irish schools done by Hernandez et al. [12] who proposed and applied a methodology to develop an energy rating system for primary Irish schools depending on measured and calculated ratings of some selected school, and researchers showed both advantages and disadvantages of the proposed rating system.

\section{Case Studies}

Three school buildings located in north suburbs of Amman city were selected to be analyzed and studied, which were built in the period of 1995-2008, AlMorooj Secondary School for Girls in Shafa Badran, Iskan AlJamiah Secondary School for Girls and Thuqan Alhindawi Secondary School for Boys. Total number of classrooms is 15, 27 and 16, respectively. Heating type for all three schools is: no heating, kerosene heaters and central heating, respectively. All of the studied schools have 419, 1,146 and 569 students, respectively. In this article, AlMorooj Secondary School for Girls will be studied.

\subsection{Climatic Data}

Studied schools are all located in a region that is mostly similar in its environmental and climatic context. Fig. 2 shows the temperature profile of the region where all the studied schools located. The climatic data included are monthly temperature profile, monthly relative humidity and monthly solar radiation, which are the main external variables that affect the way to achieve thermal comfort inside schools as a function of fuel consumption. This is evident if the three external climatic variables are viewed as the container in which the controlled classroom environment is confined in.

Detailed theoretical information about climate could be found in Refs. $[6,15,16]$.

\subsection{Method and Instrumentation}

A summary of the methods and instrumentation used are summarized as follows:

\subsubsection{Data Logger}

The M451181 data logger was used for field measurements, which can measure air velocity, temperature, relative humidity, air volume and wet bulb temperature at a time with an acceptable range of accuracy and resolution appropriate for the field study of schools. Data logger memory can record 2,400 readings in auto mode and 99 readings in manual mode.

\subsubsection{Questionnaires}

The comfort survey covered almost four parts:

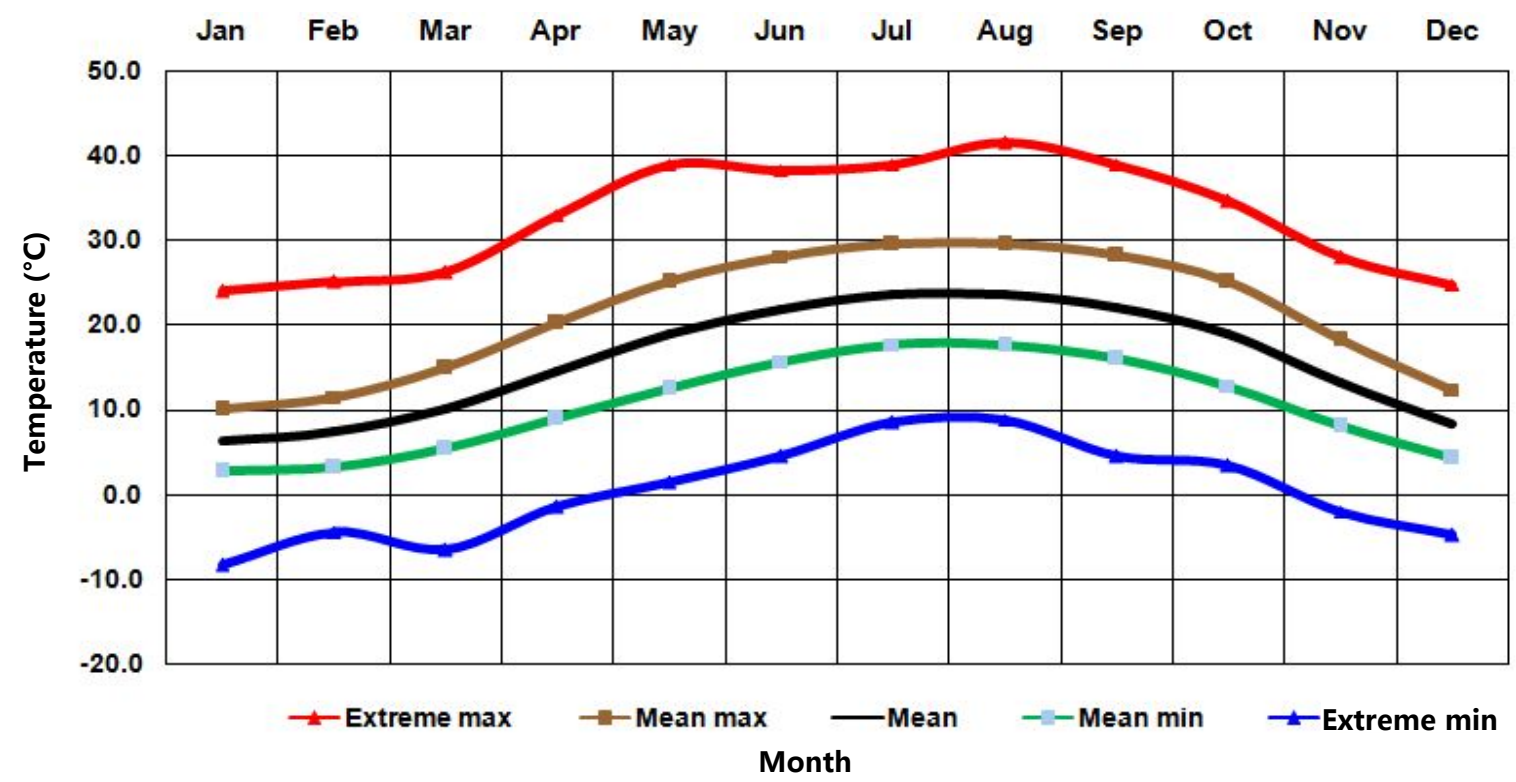

Fig. 2 Mean, minimum and maximum monthly temperatures for Amman city. 
(1) Current status of thermal comfort: the student was asked to vote for his subjective evaluation of the current status of comfort, and the ASHRAE thermal sensation scale was used as shown in Table 1, which was assumed that the categories $(-1,0,+1)$ votes are considered to express thermal comfort zone, or thermal satisfaction according to the ASHRAE thermal comfort definition. This is only for students' subjective evaluations;

(2) Modification of clothing: the student was asked to state any behavioral actions during classroom hours in order to achieve personal subjective thermal comfort and this question was divided into further sub alternatives like: major modification on clothing and minor modification on clothing (putting on); major modification on clothing and minor modification on clothing (putting off); and finally, no modifications at all;

(3) Current status of windows: this question dealt with the current status of windows and if there were any modifications that have been made by the students in order to modify subjective sensation of comfort. The three subcategories were: windows were opened during the last hour of classroom hours; windows closed during the last hour of the lesson in the classroom; no any modification of the window at all;

(4) The McIntyre preference scale was used to measure subjective attitudes, and the question asked was: just right now how would you prefer to be: warmer, cooler, no change. In this case, an answer of "no change" indicates thermal comfort satisfaction, while an answer "warmer" indicates discomfort of feeling cold, or discomfort of feeling hot if the answer was "cooler".

\subsubsection{Other Variables}

Clothing is assumed to be standard clothing according to the uniform the girls put on in the school with a light sweater and in some cases a pullover.

\subsection{Metabolic Rate}

Metabolic heat which is related directly to human activity in the surveyed classrooms was assumed to be "light activity in a seated position" and this corresponds to 1.2 met, which means $75 \mathrm{~W} / \mathrm{m}^{2}$.

Questionnaire format was tested before it could be applied in the field survey. Necessary modifications were made after the questionnaire testing.

\section{Results and Discussions}

Fig. 3 shows the general plan layout where Classrooms A and B are indicated.

Public school buildings which are mainly supervised and connected formally with the ministry of education use two main types of heating, regardless of periods and times of use which necessarily follow the manager of each school individually.

Two main types of heating are used, and the first one is central heating. Few schools nationwide use this type of heating, and if so, certain quantity of fuel is supplied by the ministry of education to operate the central heating plant. Often, in modern school buildings, architects include, in their designs, central heating systems to ensure acceptable thermal comfort levels indoors.

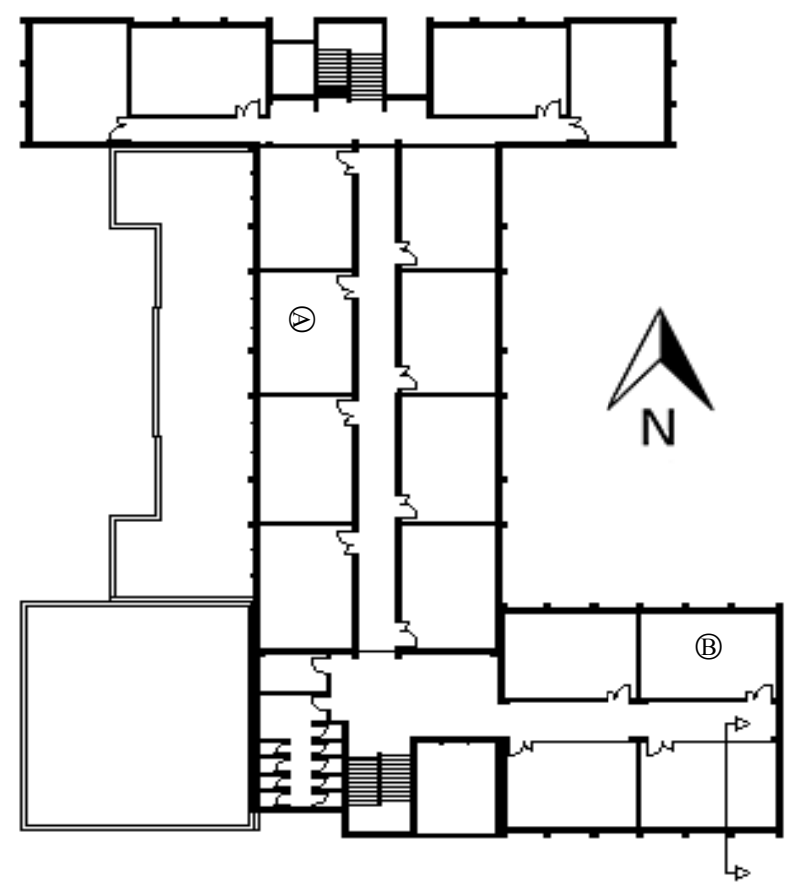

Fig. 3 Plan layout of Almorooj Secondary School, Amman. Source: Classrooms A and B were studied and analyzed, author, 2011. 
The second type of heating is using kerosene heaters of specific type. Also certain quantities of fuel are supplied for each school to heat educational spaces. Rules are established to decide the quantity of fuel each school should have, and it will be explained later (Eq. (1)). For each school without central heating plants, kerosene heaters are used instead.

According to direct observation, kerosene heaters are inefficient devices to provide classroom with heat in a safe secure way. This is due to many facts: the first one is that the kerosene heater has a low heating capacity as shown in Table 2; second, they are considered unsafe in terms of fire risks and this is evident specially if we explore fire accidents recorded by the directorate of civil defense in Jordan, last accident recorded in schools were in Almafraq schools [17]; third, emission of environmental pollutants $\mathrm{CO}_{\mathrm{x}}$, $\mathrm{NO}_{\mathrm{x}}$, is considered to be large and exceeds unacceptable levels, or they exceed the figures set by international standards. This leads definitely to environmental pollution inside classrooms, which creates unhealthy environment for students and decrease the potentiality of productive educational environments. Table 2 shows detailed description of kerosene heaters used in public school buildings in Jordan.

Heating season starts on November 15 th and ends on March 15th each year. This fraction is almost $20 \%$ of the year and $71 \%$ of the academic year given that the total days of the academic year are 105 days from August 15th and ends in June 15th of each year.

The quantity of fuel to be supplied for each school has a certain equation set by the ministry of education:

$$
\begin{aligned}
& Q=(\text { Number of Heaters }) \times \\
& (\text { Heating period }(\text { days })) \times 1.5
\end{aligned}
$$

where, $Q$ is the fuel quantity in liters for the total heating period and this applies for kerosene and diesel only.

The most common heating systems types used in public schools of Jordan ministry of education are kerosene heaters, and specifications are shown in Table 2.

Therefore, if we consider the heating period as shown in Fig. 4, this will result in almost 75 days. For each heater, there will be:

$$
\mathrm{Q}=75 \times 1.5=112.5 \mathrm{~L} \text { of kerosene }
$$

Table 2 Detailed description of Kerosene heaters used in schools.

\begin{tabular}{ll}
\hline $\begin{array}{l}\text { Kerpsene heater } \\
\text { (specification) }\end{array}$ & Capacity \\
\hline Tank system & Single tank \\
Tank capacity $(\mathrm{L})$ & 4.5 \\
Heat output $(\mathrm{kcal} / \mathrm{h})$ & 2,250 \\
Fuel consumption $(\mathrm{L} / \mathrm{h})$ & 0.25 \\
Dimension $(\mathrm{mm})$ & $330 \times 330 \times 470$ \\
Heating area $\left(\mathrm{m}^{2}\right)$ & $14-16$ \\
Gross weight $(\mathrm{kg})$ & 5.5 \\
\hline Source: $\mathrm{http}: / / \mathrm{www} \cdot$ gtrade.or.kr/buyer.product/Kerosene-heater.
\end{tabular}

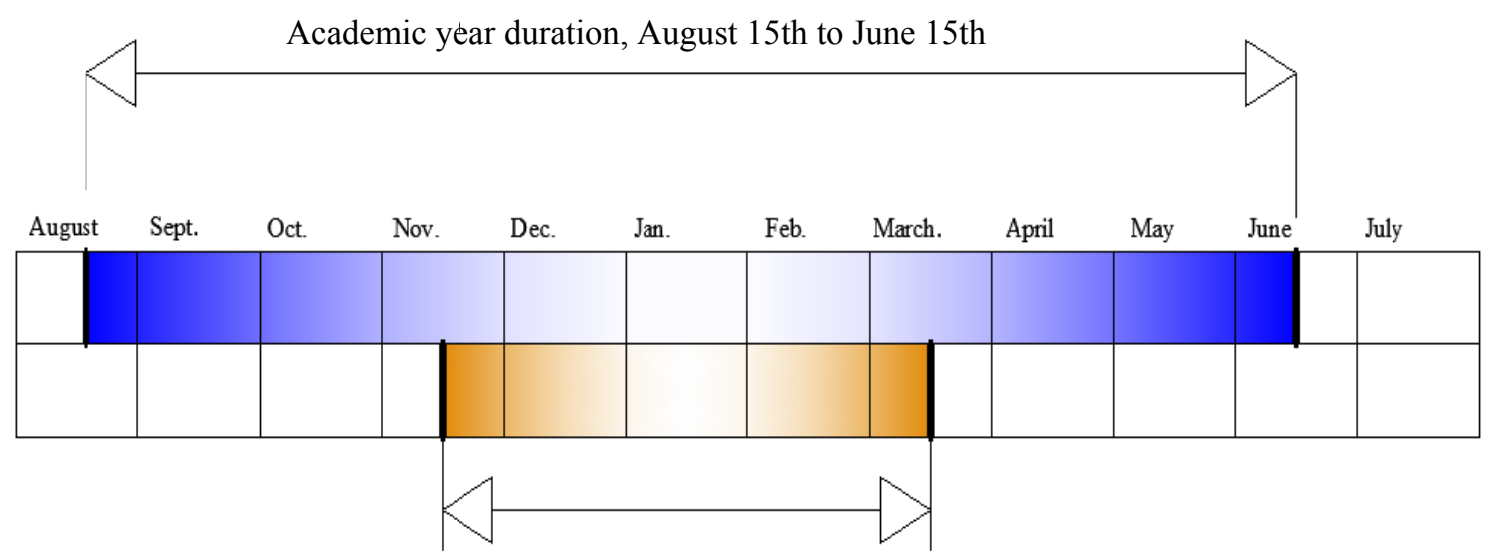

Heating period in schools, November 15 th to March 15 th

Fig. 4 Heating period in public schools as a proportion of the total academic year duration. 

Public School Buildings in Jordan

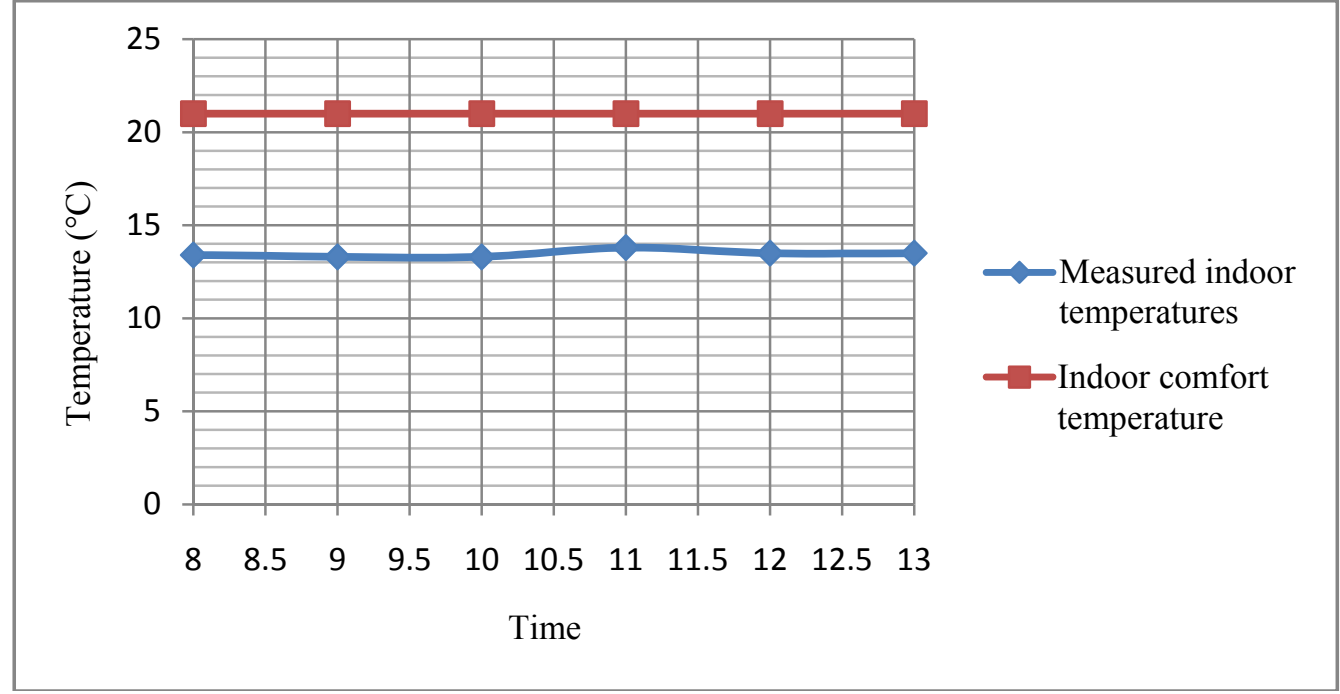

Fig. 5 Differences between measured indoor temperatures and comfort temperatures during classroom lessons.

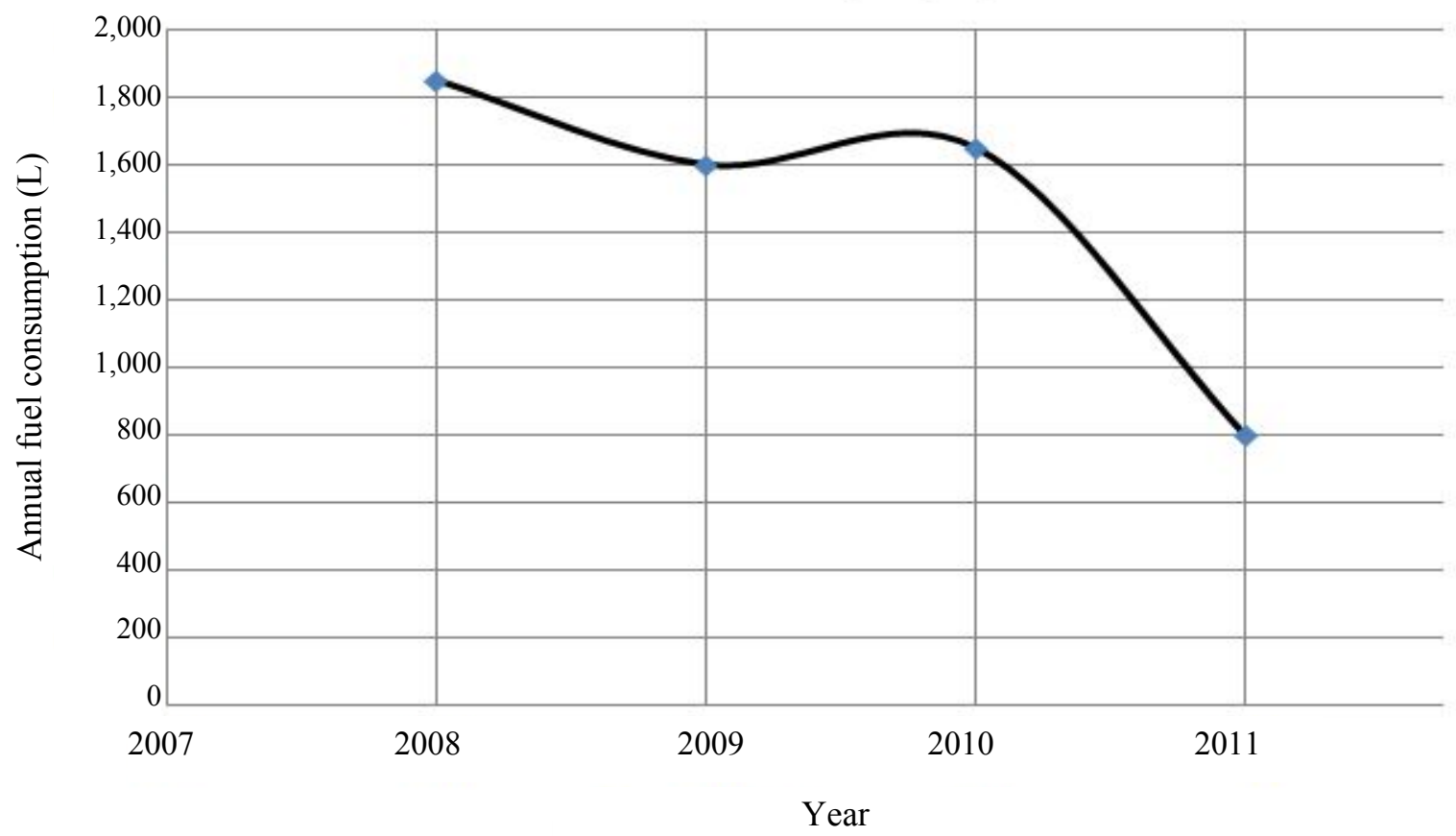

Fig. 6 Annual fuel consumption for 4 years, Almorooj Secondary School.
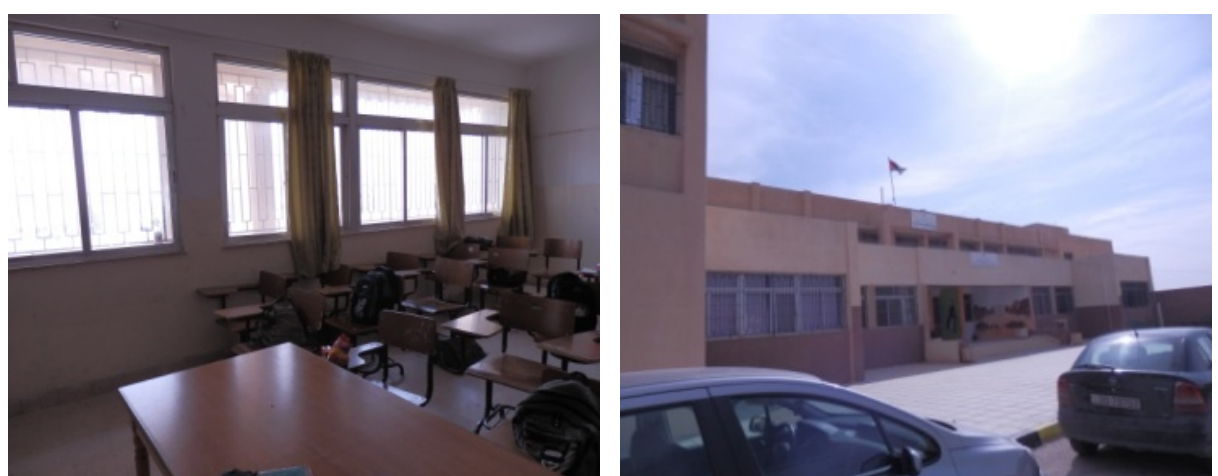

Fig. 7 View of the school and indoor classroom environment. Source: author, 2011. 
And this is for one heater only which assumes that, for the whole heating period, one heater will be sufficient for one classroom.

For Almorooj School, there are almost 24 kerosene heaters, which mean 2,700 L of kerosene. Fig. 5 shows indoor comfort temperature profile and actual indoor temperature measurements when classrooms were unheated, while Fig. 6 shows the annual fuel consumption in three years for Almorooj School.

Classrooms A and B were chosen for field measurements. Dry bulb temperature, relative humidity and external temperature were recorded using data logger. Table 3 shows main features of the analyzed classroom in Almorooj Secondary School located in Shafa Badran neighborhood. Fig. 7 shows images of the school and the studied classrooms.

As shown in Fig. 8, Classroom A has votes towards thermal comfort much less than Classroom B, but majority of occupants in both classrooms voted from -1 to -3 which means a state of discomfort and this is normal as there were no efficient heating, only one kerosene heater supposed to heat a total volume of $128.8 \mathrm{~m}^{3}$.

Table 3 Main characteristics of the studied classroom in Almorooj Secondary School for Girls.

\begin{tabular}{lll}
\hline Classroom & A & B \\
\hline Students capacity & 26 & 26 \\
Volume $\left(\mathrm{m}^{3}\right)$ & 128.8 & 128.8 \\
Area $\left(\mathrm{m}^{2}\right)$ & 44.8 & 44.8 \\
Height $(\mathrm{m})$ & 3.22 & 3.22 \\
Glazed area/façade area $(\%)$ & $29 \%$ & $29 \%$ \\
Window orientation & West & North \\
Heating fuel type & Kerosene & Kerosene \\
Ventilation & Natural & natural \\
\hline
\end{tabular}

Source: author, 2012.

Frequency of votes for Classrooms A and B

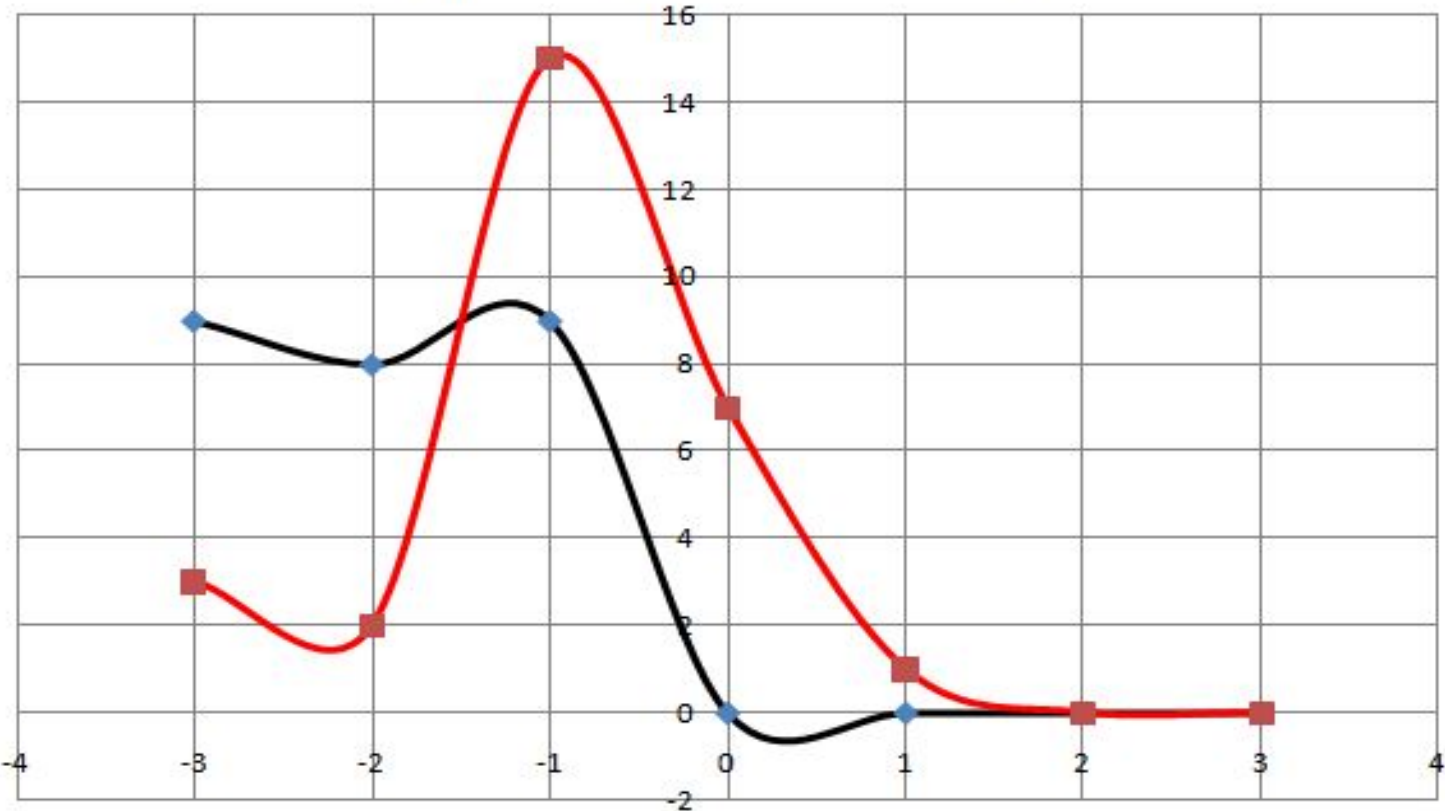

$\longrightarrow-$ Frequency of votes, Classroom A $\quad-$ Frequency of votes, Classroom B

Fig. 8 Frequency of votes for the studied Classrooms $A$ and $B$. 
Fig. 9 confirms that, when students were asked about whether the thermal environment was acceptable or not, it shows the frequencies of votes for both which they voted for "not acceptable" and those who voted "acceptable".

This conforms to the general hypothesis drawn up.

Classrooms A and B were selected in Almorooj Secondary School to be studied.

The analysis of the collected data via questionnaires shows an evident dissatisfaction with the thermal environment in Almorooj classrooms. This is clear if we look at the diagram in Figs. 9 and 10. High dissatisfaction with the thermal environment is directly correlated with the degree of acceptability of the thermal environment. Most of the students show low acceptability percentage with the thermal environment. But if we look at the measured temperatures and relative humidity, we see that the measured temperatures are below the comfort temperatures range according to the ASHRAE standards. The temperatures did not exceed $14{ }^{\circ} \mathrm{C}$, this means that, still, the thermal environment must be raised until it reaches $20^{\circ} \mathrm{C}$.

The heating system in the classroom is described in previous part of the research, but according to the interviewed managers, teachers and students, it is not only inefficient, but dangerous and risky. It leaves strong smog and polluted indoor air quality.

Interviewed students statements may be summarized as that they are dissatisfied with the thermal environment and the heating system adopted in the classrooms. Solutions are to be adopted to resolve the problem thermal comfort dissatisfaction through multi level solutions.

\section{Conclusions and Recommendations}

The previous analysis of the surveyed classroom environments shows that much work has to be done in order to improve the thermal comfort levels in classrooms. This will not be achieved unless a comprehensive strategy is adopted for such

Frequencies of acceptability of the thermal environment

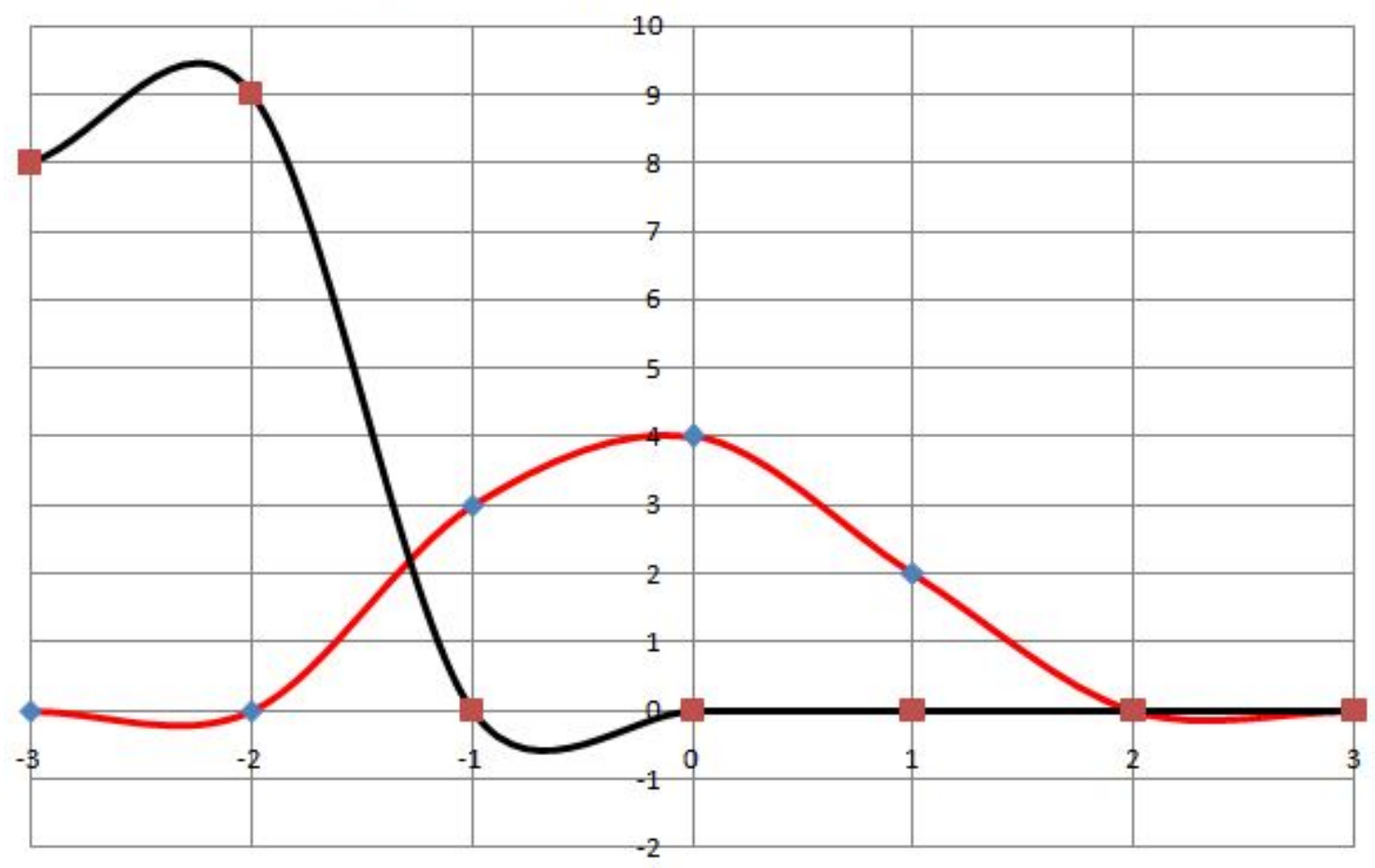

$\longrightarrow$ Acceptable (Classroom A) - -Not acceptable (Classroom A)

Fig. 9 Votes about whether the thermal environment of Classroom $A$ is acceptable or not. 
Frequency of thermal environment acceptability (Classroom B)

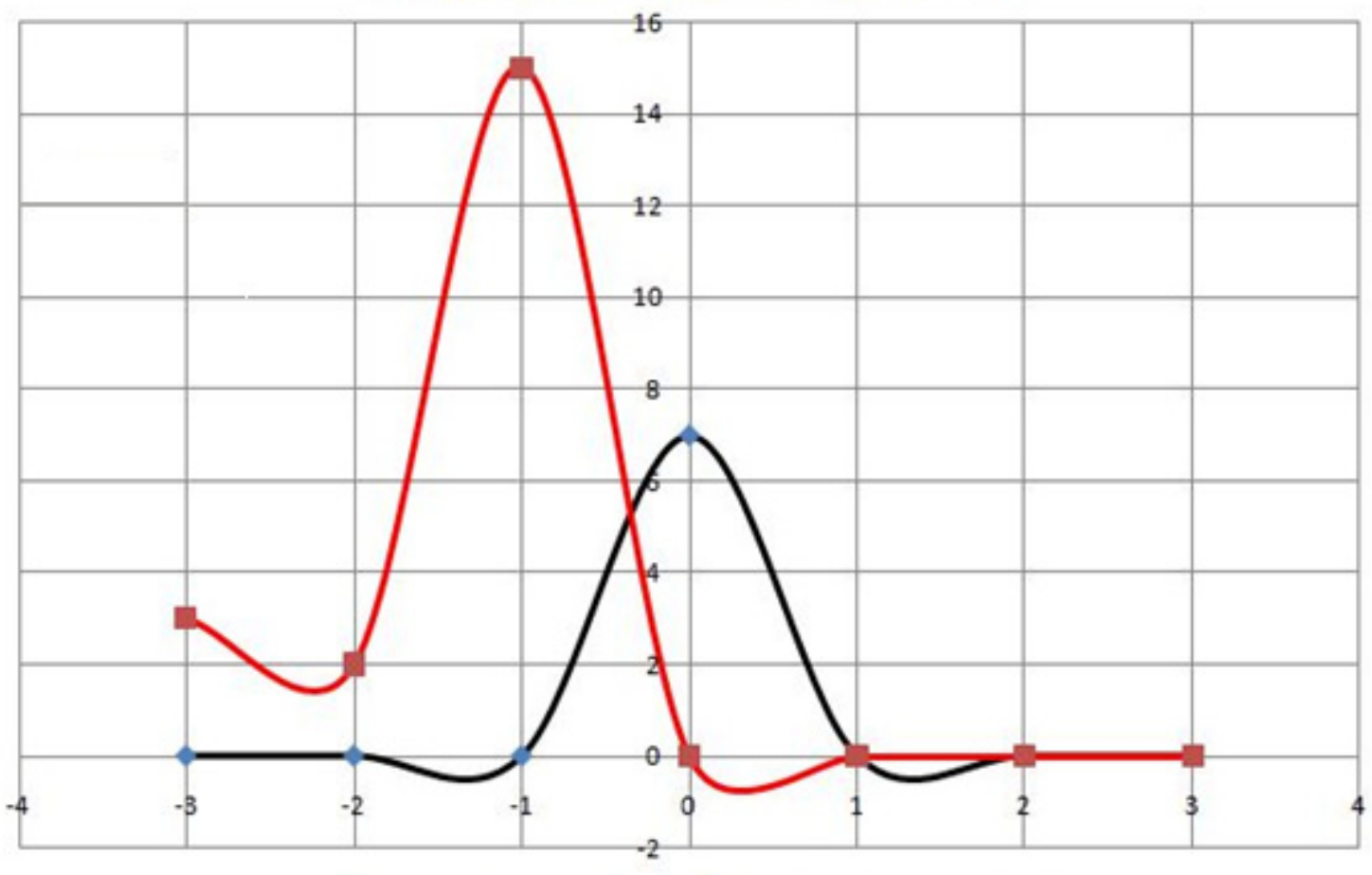

Acceptable (Classroom B) - - Not acceptable (Classroom B)

Fig. 10 Frequency of thermal environment acceptability for Classroom B.

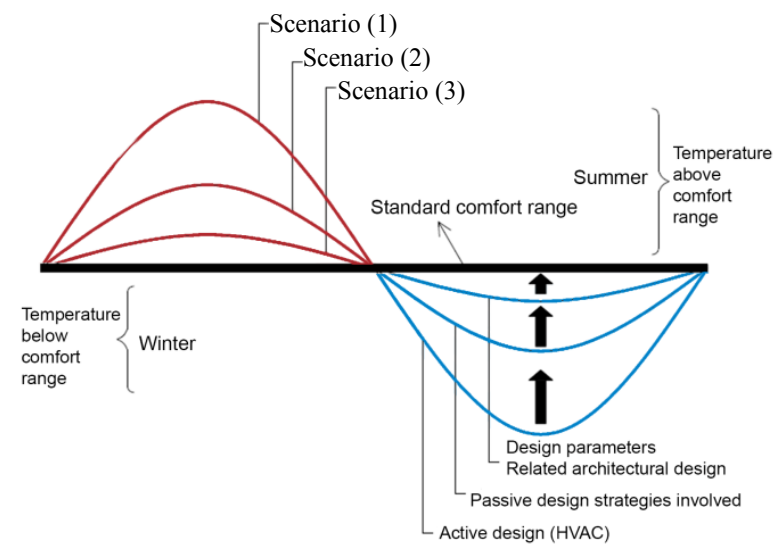

Fig. 11 Reducing energy consumption and maximizing thermal comfort by adapting one or more of the three scenarios.

improvements. The growing strategy must be initiated starting from the results obtained from the analysis explained previously.

Many problems could be concretized here regarding the dynamic relationship among fuel consumption by quantity and type, thermal comfort levels and building fabric and design.

This multi level and hierarchical structure of the relationship between the three variables can compose a very harmonic relationship among them in such a manner that provides thermal comfort with the minimum energy consumption and the best designed building fabric, achieving, at the same time, other measures like indoor air quality and safe educational environment.

Such problems may be summarized in the following:

(1) The problem of thermal comfort dissatisfaction in the cold season is evident and it needs proper solutions. Thermal comfort in other periods of the academic year is not investigated and this may open the door for future extension of this work;

(2) System and type of heating do not guarantee acceptable indoor air quality and this is reflected directly to the dynamic relationship among thermal comfort and energy consumption;

(3) Methods must be adopted to reduce complete dependence upon fossil fuel consumption and its related to $\mathrm{CO}_{\mathrm{x}}$ emissions. Starting from Fig. 11, one can quantify how much passive solar heat can 
contribute to the heating of classrooms other than fossil fuels. This means that the net fuel quantity needed in this case can be measured:

Net heat required by fossil fuels $=$ Total heat needed - Heat contributed by passive design techniques

(4) Windows in classroom design were neglected in a way that the observer can detect the direct negative effects in the physical environment of the classroom. This is evident when illumination levels were measured inside the classroom, which showed low illumination levels;

(5) The problem of optimal relationship between illumination and design for thermal comfort is dominant problem which is considered as one of the main problems in optimizing the relationship between illumination and heating;

(6) Standards were not applied when designing for educational environment, and this problem affects comfort inside classrooms.

The general scenario for resolving such problems may be summarized in Fig. 11, which explains the multi level strategy that could be followed in order to achieve optimum dynamic relationship between thermal comfort, energy consumption and building fabric.

The results of the study require a set of steps that could improve comfort levels in classroom wings in the studied schools:

- Strategies of passive design should be enhanced in order to improve comfort levels in the classrooms. This strategy reduces dependence on fossil fuels for heating;

- Building fabric should be studied in a more precise way for thermal insulation, especially in cold climatic zones in Jordan, while for hot regions in Jordan, different strategies must be developed and this may be implemented in future research work;

- A need to adopt energy certificates for schools is off prime importance so as to keep clear and reliable information about energy consumption and comfort levels in schools, and the certificate has many benefits for establishing the relationship between comfort, energy consumption and cost as well;

- Passive design for public schools could be developed through a research project that takes each climatic zone separately and develop its particular passive design strategies, and this is of great importance, which differs from the similar school prototypes which are built everywhere in Jordan regardless the distinct climatic differences among each climatic zone.

\section{Acknowledgments}

This research work was started and completed during the sabbatical leave granted to Dr. Abdulsalam A. Alshboul from the University of Jordan during the academic year 2010-2011. Many thanks are due to the University of Jordan for financial support and for offering all facilities to complete this research.

\section{References}

[1] Annual Report, Ministry of Education, Amman, 2010.

[2] D. Watson, Energy Conservation through Building Design, McGrawHill Book Company, New York, 1979.

[3] D. Daum, F. Haldi, N. Morel, A personalized measure of thermal comfort for building controls, Building and Environment 46 (1) (2011) 3-11.

[4] ASHRAE, ASHRAE Handbook, ASHRAE, Atalanta, 1985.

[5] N. Letchner, Heating Cooling Design Strategies for Architects, John Wiley \& Sons, New York, 1990.

[6] D.K, Wiles, Energy Winter and Schools, Lexington Books, Lexington, 1979.

[7] A. Hildon, A.J. Howrie, A case study in energy efficiency: Sutton coldfield deanery first and middle schools, Energy and Buildings 5 (2) (1982) 117-125.

[8] M. Santamouris, C.A. Balaras, E. Dascali, A. Argiriou, A. Gaglia, Energy consumption and the potential of energy conservation in school buildings in Hellas, Energy 19 (6) (1994) 653-660.

[9] V. Butala, P. Novak, Energy consumption and potential energy savings in old school buildings, Energy and Buildings (29) (1999) 241-246.

[10] U. Desideri, S. Proietti, Analysis of energy consumption in the high schools of a province in central Italy 2002, Energy and Buildings 34 (10) (2002) 1003-1016.

[11] I. Cooper, Heating standards or energy conservation? A review of British Legislation for school buildings, Applied Energy 15 (1983) 247-272. 


\section{Public School Buildings in Jordan}

[12] P. Hernandez, K. Burke, J.O. Lewis, Development of energy performance benchmarks and building energy ratings for non-domestic buildings: An example for Irish primary schools, Energy and Buildings 40 (3) (2008) 249-254.

[13] J.N. Chalky, H.R. Cater, Thermal Environment, Architectural Press, London, 1968.

[14] D. Watson, K. Labs, Climatic Design Energy Efficient Buildings and Practices, McGrawHill Book Company,
New York, 1983.

[15] Guidelines for Environmental Design and Fuel Conservation in Educational Buildings, Design Note 17, DES (Department of Education and Science), Architects and Building Branch, London, 1979.

[16] Annual report, Dec. 14, 2011, Jordan Civil Defense Directorate, Amman, Jordan.

[17] Architectural Design Guideline for Government Schools, Ministry of Education, Amman, Jordan, 2000. 